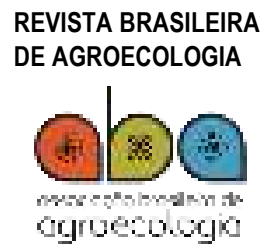

ISSN: $1980-9735$

\title{
GERMINAÇÃO E CRESCIMENTO INICIAL DE CAPUCHINHA EM DIFERENTES CONDIÇÕES DE CULTIVO
}

1 Doutoranda no Programa de PósGraduação em Meio Ambiente e Desenvolvimento Regional,

Universidade Anhanguera-Uniderp, Campus Agrárias; E-mail: pamellasdepp@hotmail.com;

${ }_{2}$ Professor Pesquisador, Programa de Pós-Graduação em Meio

Ambiente Desenvolvimento

Regional, Universidade AnhangueraUniderp, Campus Agrárias;

${ }^{3} E$-mail:

akmorbeckoliveira@gmail.com,

4 E-mail: rosematiasc@gmail.com;

5 Professora Pesquisadora,

Programa de Pós-Graduação em Produção e Gestão Agroindustrial, Universidade Anhanguera-Uniderp, Campus Agrárias;

denise.pedrinho@anhanguera.com

Recebido em:

24/04/2018

Aceito para publicação em:

11/11/2018

Correspondência para:

pamellasdepp@hotmail.com Pâmella Gonçalves da Silva ${ }^{1}$, Ademir Kleber Morbeck de Oliveira $^{2,3}$,
Rosemary Matias $^{2,4}$ e Denise Renata Pedrinho ${ }^{5}$

\section{RESUMO}

Objetivou-se avaliar a germinação e crescimento de capuchinha em diferentes condições ambientais. Os resultados indicaram melhor germinação em substrato vermiculita em $25^{\circ} \mathrm{C}$, entre dois e cinco dias. $\mathrm{O}$ melhor crescimento inicial foi com substrato areia em 20 e $25^{\circ} \mathrm{C}$. Em casa de vegetação o tratamento controle e substrato com adição de esterco ovino se destacaram, em duas luminosidades, demonstrando adaptação a ambientes variáveis de cultivo.

Palavras-chave: Tropaeolum majus. Hortaliças Não-convencionais. Vigor de Sementes. Adubação Orgânica.

\section{ABSTRACT}

The objective was to evaluate the germination and growth of nasturtium in different environmental conditions. The results indicated a better germination in vermiculite substrate at $25^{\circ} \mathrm{C}$, between two and five days. The best initial growth was in substrate sand at 20 and $25^{\circ} \mathrm{C}$. In green house, the control treatment and substrate with addition of sheep manure stood out, in both luminosities, demonstrating adaptation to diverse environments.

Keywords: Tropaeolum majus. Unconventional Vegetables. Seed Vigor. Organic Fertilization. 
As Plantas Alimentícias Não Convencionais (PANC's) são espécies rústicas, de fácil plantio, propagação e adaptação às diferentes condições ambientais, sendo normalmente o solo e o clima fatores não limitantes; por esse motivo, podem ser cultivadas de forma agroecológica e/ou orgânica (KINUPP e BARROS, 2007).

No Brasil, o cultivo e consumo das PANC's vem diminuindo com o passar dos anos, resultado do crescente consumo de alimentos industrializados e cultivo intensivo de culturas convencionais. Esta situação influência de forma considerável o hábito alimentar da população, gerando perdas na identidade cultural, em relação ao consumo de alimentos locais e/ou regionais (MAPA, 2010). Desta forma, faz-se necessária a disseminação de conhecimentos acerca dos benefícios deste tipo de alimentação.

Uma das espécies precursoras na retomada do consumo e cultivo das PANC's é Tropaeolum majus L. (Tropaeolaceae), conhecida como capuchinha. As folhas, talos e flores são comestíveis e utilizadas no preparo de diversos pratos, principalmente pelo sabor fresco e picante das flores, que lembra o agrião (Nasturtium officinale R. Br.), conferindo um toque exótico e belo às saladas (RIBEIRO et al., 2012). As folhas e flores também possuem uso medicinal, por serem ricas em compostos fenólicos, flavonoides e vitamina C, o que confere à planta atividade antioxidante (GASPAROTTO et al., 2009).

Por suas diferentes características, sendo uma delas a rusticidade e pequena necessidade de manejo, é considerada uma excelente alternativa de cultivo para pequenos produtores, por apresentar um baixo custo de produção e, consequentemente, gerar aumento de renda familiar. Contudo, de maneira geral, essa hortaliça ainda não possui uma produção significativa para que possa ser explorada comercialmente.

A germinação e formação das plântulas são aspectos importantes e com grande relevância no estudo de espécies que apresentam potencial econômico, pois envolvem um conjunto de eventos fisiológicos, ocorrendo em adequada condição de temperatura, substrato e luminosidade, por exemplo (MARCOS FILHO, 2005; BRASIL, 2009).

Por essas características, foram realizados dois ensaios. No primeiro, objetivou-se avaliar a germinação das sementes de capuchinha e formação de plântulas em seis temperaturas e três substratos, em câmara de germinação. No segundo ensaio, realizado em casa de vegetação, avaliou-se o crescimento inicial em duas luminosidades e cinco substratos orgânicos, em diferentes proporções.

As sementes utilizadas pertencem ao mesmo lote, data de fabricação e validade, obtidas em casa de produtos agropecuários no município de Campo Grande, Mato Grosso do Sul. O experimento de germinação foi desenvolvido no Laboratório de Pesquisa em Sistemas Ambientais e Biodiversidade e o cultivo, realizado em casas de vegetação, localizadas na Universidade Anhanguera-Uniderp, Campo Grande (2026'20.64'S; 5432'26.78"O).

O teste de germinação foi realizado em esquema fatorial de $3 \times 6$ ( 3 substratos e 6 temperaturas), com delineamento inteiramente casualizado. Os substratos foram papel (Germitest), areia lavada e vermiculita, acondicionados em caixas plásticas transparentes $(11 \times 11 \times 3,5 \mathrm{~cm})$. As sementes, após imersas em hipoclorito de sódio por cinco minutos e lavadas em água corrente por um minuto, foram colocadas sobre os substratos, sendo 20 sementes por caixa, quatro repetições por tratamento.

O papel foi previamente umedecido (2,5 vezes seu peso), utilizando-se uma solução aquosa de fungicida de contato do grupo químico das hidantoínas a $0,1 \%(\mathrm{~m} / \mathrm{v})$ (BRASIL, 2009) e os demais substratos, 2,0 vezes a sua massa em água; quando necessário, foram umedecidos com água destilada.

As temperaturas foram $20,25,30$ e $35^{\circ} \mathrm{C}$ e, $20-30$ e $25-35^{\circ} \mathrm{C}$, com fotoperíodo de $12 \mathrm{~h}$ de luz branca, em câmaras de germinação, com avaliação diária, durante 10 dias, considerando-se germinação a emissão de raiz primária de $2 \mathrm{~mm}$. Após o término do experimento, as sementes não germinadas foram submetidas ao teste de viabilidade de tetrazólio a 1\% em solução aquosa (BRASIL, 2009).

As avaliações contaram da germinação (G\%) e o vigor das sementes, por meio do índice de velocidade de germinação (IVG) e tempo médio de germinação (TMG), medido em dias. Foi, também, avaliado o desenvolvimento inicial das plântulas normais no sétimo dia após a germinação das primeiras 
sementes, sendo medidas $(\mathrm{mm})$ a raiz primária (colo da plântula até o ápice meristemático do sistema radicular) e parte aérea (colo da planta até o ápice, primeira divisão da gema apical), por intermédio de paquímetro digital.

Os dados obtidos (geminação e crescimento) foram transformados, de acordo com os testes de normalidade e homogeneidade de variâncias, para a realização da ANOVA, sendo apresentados dados não transformados, para facilidade de compreensão.

Em casa de vegetação, a semeadura foi realizada em bandejas de poliestireno expandido (128 células) com substrato comercial, uma semente por célula. Após 15 dias de desenvolvimento, foi realizado o transplante das mudas para vasos com capacidade para $3 \mathrm{~kg}$ (altura de $15 \mathrm{~cm}$, largura superior de $20 \mathrm{~cm}$, largura inferior, 14,5 cm). Cada unidade experimental era composta por 4 vasos (por luminosidade), sendo que cada um representava uma unidade de observação, totalizando 80 vasos.

O cultivo foi realizado no período de março a outubro de 2016, com experimento instalado sob duas intensidades luminosas ( 50 e $70 \%$ de luminosidade) obtidas por meio do uso de telas de sombreamento produzidas em filamento de polietileno. Os substratos tiveram como base solo arenoso (SA) e cinco tipos de adubos orgânicos, previamente curtidos (Cama de Frango - CF; Esterco Bovino - EB; Ovino - EO; Coelho - EC; e, Torta de Filtro - TF), incorporadas ao solo. O delineamento experimental seguido foi o inteiramente casualizado, em esquema fatorial de $2 \times 10$ (2 luminosidades e 10 substratos).

Os tratamentos foram: T1 - Testemunha (SA); T2 - Testemunha Química (SA + 1,5 g de N, $5 \mathrm{~g}$ de P e 2 g de K); T3 - 80\% SA + 20\% TF; T4 - 60\% SA + 40\% TF; T5 - 80\% SA + 20\% CF; T6 - 80\% SA + 20\% EB; T7 - 80\% SA + 20\% EO; T8 - 60\% SA + 40\% EO; T9 - 80\% SA + 20\% EC; e T10 - 60\% SA + 40\% EC. A análise de crescimento inicial foi realizada por intermédio da medida da base do caule, até a última divisão da gema apical, com o auxílio de régua graduada $(\mathrm{cm})$, aos 15 dias após o transplante.

Os resultados foram submetidos à análise de variância. A comparação das médias entre os tratamentos foi através dos intervalos de confiança (5\%) por meio do Teste $\mathrm{T}$, realizada com auxílio do programa Assistat (SILVA e AZEVEDO, 2016).

No primeiro ensaio, avaliando-se a interação entre substrato e temperatura, verifica-se que ocorreu correlação entre os diferentes parâmetros; porém, apenas o substrato areia, temperatura $20-30^{\circ} \mathrm{C}$ e o substrato vermiculita, $25^{\circ} \mathrm{C}$, apresentaram o melhor conjunto de dados, com maior germinação e vigor das sementes (alto IVG e menor TMG). As demais apresentaram resultados parcialmente adequados, tais como melhor germinação, substrato areia em $25^{\circ} \mathrm{C}$, embora com menor IVG e maior TMG (Tabela 1).

Tabela 1. Germinação (G), índice de velocidade de germinação (IVG) e tempo médio de germinação (TMG) (dias), sementes de capuchinha em diferentes temperaturas $\left({ }^{\circ} \mathrm{C}\right)$ e substratos. Campo Grande, 2018

\begin{tabular}{ccccccccccc}
\hline & \multicolumn{3}{c}{$\mathrm{G}(\%)$} & \multicolumn{3}{c}{ IVG } & \multicolumn{3}{c}{ TMG (dias) } \\
\hline Interação & areia & Papel & verm* & areia & papel & verm* & areia & papel & verm* \\
\hline $20^{\circ} \mathrm{C}$ & $47^{\mathrm{bB}}$ & $42^{\mathrm{bB}}$ & $57^{\mathrm{bA}}$ & $3,5^{\mathrm{cB}}$ & $3,3^{\mathrm{bB}}$ & $5,1^{\mathrm{bA}}$ & $5,4^{\mathrm{bB}}$ & $5,4^{\mathrm{bB}}$ & $4,6^{\mathrm{aA}}$ \\
$25^{\circ} \mathrm{C}$ & $80^{\mathrm{aA}}$ & $65^{\mathrm{aB}}$ & $72^{\mathrm{aAB}}$ & $5,8^{\mathrm{bB}}$ & $5,6^{\mathrm{aB}}$ & $7,1^{\mathrm{aA}}$ & $5,4^{\mathrm{bB}}$ & $4,4^{\mathrm{aA}}$ & $4,3^{\mathrm{aA}}$ \\
$30^{\circ} \mathrm{C}$ & $45^{\mathrm{bA}}$ & 0 & $7,5^{\mathrm{dB}}$ & $3,3^{\mathrm{CA}}$ & 0 & $0,5^{\mathrm{dB}}$ & $4,3^{\mathrm{aA}}$ & 0 & $7,3^{\mathrm{bB}}$ \\
$35^{\circ} \mathrm{C}$ & 0 & 0 & 0 & 0 & 0 & 0 & 0 & 0 & 0 \\
$20-30^{\circ} \mathrm{C}$ & $85^{\mathrm{aA}}$ & $20^{\mathrm{cC}}$ & $57^{\mathrm{bB}}$ & $7,3^{\mathrm{aA}}$ & $2,3^{\mathrm{bC}}$ & $4,7^{\mathrm{bB}}$ & $4,5^{\mathrm{aA}}$ & $3,6^{\mathrm{aA}}$ & $5,5^{\mathrm{bB}}$ \\
$25-35^{\circ} \mathrm{C}$ & $22^{\mathrm{CB}}$ & $22^{\mathrm{cB}}$ & $40^{\mathrm{cA}}$ & $2,3^{\mathrm{dB}}$ & $2,5^{\mathrm{bB}}$ & $3^{\mathrm{cA}}$ & $4,4^{\mathrm{aAB}}$ & $4,2^{\mathrm{aA}}$ & $5,6^{\mathrm{bB}}$ \\
\hline
\end{tabular}

*Verm = vermiculita. Médias seguidas de mesma letra (minúsculas para colunas, maiúsculas para linhas) não diferem entre si, pelo teste $t$ ( $5 \%$ de probabilidade).

Os resultados estão diretamente relacionados à utilização de substratos que possuem características distintas. Como descrito nas Regras para Análise de Sementes - RAS (BRASIL, 2009), estes substratos devem atender a exigências fisiológicas de germinação para a espécie utilizada, levando em conta aspectos como o tamanho e forma dessas sementes. Desta maneira, cada espécie pode possuir requisitos distintos.

A areia e vermiculita, por exemplo, são substratos que retém maior volume de água, possibilitando à semente uma melhor obtenção de umidade em suas diversas funções biológicas. Além 
disso, a vermiculita é totalmente estéril e não possui nenhum tipo de nutriente, tendo maior porosidade; já a areia possui uma menor porosidade devido ao pequeno diâmetro das partículas, possuindo uma maior capacidade de compactação e consequentemente, uma maior retenção superficial de água (BRASIL, 2009)

Já o substrato papel não absorve água em grande quantidade, fator relacionado a sua massa; por isso não foi adequado. Esse evento é explicado por Marcos Filho (2005), o qual afirma que, quando não ocorre uma disponibilidade hídrica suficiente, processos como a germinação podem ser prejudicados seriamente, ocasionando a morte do embrião. Os dados obtidos (Tabela 1) estão de acordo com a afirmação acima.

A perda de viabilidade verificada em algumas temperaturas, de acordo com o teste do tetrazólio, demonstra que não são indicadas temperaturas altas para as sementes da espécie, tais como $35^{\circ} \mathrm{C}$, mesmo por períodos de $12 \mathrm{hs}\left(25-35^{\circ} \mathrm{C}\right)$ (Tabela 1 ).

Segundo Marcos Filho (2005), temperaturas elevadas atuam sobre as atividades enzimáticas, muitas vezes afetando negativamente os processos, além de restringir o acesso do oxigênio, afetando seu vigor. Com isso, tendem a diminuir a percentagem de germinação, justificando os resultados obtidos, com a temperatura influenciando na velocidade de absorção de água e, consequentemente, nas reações bioquímicas. Porém, a temperatura mais adequada é dependente da espécie e de sua região de origem.

A respeito da temperatura, de acordo com Brancalion et al. (2010), a faixa de 20 a $35^{\circ} \mathrm{C}$ é a mais adequada para a germinação de sementes de espécies tropicais e subtropicais, com os resultados encontrados confirmando o valor de $25^{\circ} \mathrm{C}$. Por outro lado, as melhores taxas de germinação em temperaturas alternadas são comuns apenas para algumas espécies tropicais (CETNARSKI FILHO e NOGUEIRA, 2005).

De acordo com Bewley et al. (2013), espécies que possuem taxas significativas de germinação em temperaturas alternadas possuem mecanismos enzimáticos específicos que funcionam em diferentes temperaturas. Essa situação é resultado de adaptações ecológicas ao ambiente, permitindo grande distribuição geográfica e/ou adaptações às flutuações de temperaturas do hábitat, indicando plasticidade ambiental. Esse mecanismo, uma estratégia de adaptação, permite que os vegetais de uma mesma espécie possam ocupar áreas distintas, em termos ecológicos, o que é uma vantagem ambiental.

O TMG confirma que a espécie pode rapidamente ocupar determinadas áreas, com produção de plântulas entre 3 e 6 dias (Tabela 1), confirmando indicações de Brasil (2009). Essa situação pode possibilitar uma alternativa viável de cultivo, facilitando o estabelecimento das plantas no campo, por exemplo.

Entretanto, para a obtenção de melhores resultados nas taxas de germinação e vigor em laboratório, o recomendado é a utilização de substrato areia com temperaturas de $25^{\circ} \mathrm{C}$ ou alternadas de $20-30^{\circ} \mathrm{C}$ e/ou substrato vermiculita, $25^{\circ} \mathrm{C}$.

Embora as recomendações das RAS, apontam para a espécie que os substratos sobre papel, entre papel e entre areia, como os mais indicados. Entretanto, os resultados apresentados indicam que o substrato papel não é o mais adequado, sendo ainda mais eficaz a disposição das sementes sobre a areia, ao invés de entre areia. Em relação às temperaturas, a recomendação é 15,20 e $20-30^{\circ} \mathrm{C}$; porém, na menor temperatura utilizada, $20^{\circ} \mathrm{C}$, ocorreu uma menor taxa e apenas $20-30^{\circ} \mathrm{C}$ se destacou, além de $25^{\circ} \mathrm{C}$.

Os diferentes resultados apresentados entre as RAS e o presente estudo podem ser justificados a partir da origem das sementes utilizadas. Neste trabalho, as sementes foram compradas em casas agropecuárias locais, pertencendo a lotes distintos, em relação às utilizadas pelas RAS. De acordo com Oliveira et al. (2015), a origem das sementes pode influenciar os processos de germinação das mesmas, afetando seu vigor.

Vale ressaltar que espécies rústicas apresentam uma maior variabilidade de suas características, o que interfere em suas percentagens de germinação. Por outro lado, aspectos como as 
interações desenvolvidas entre os substratos e temperaturas durante o experimento também influenciam nos resultados.

Essa situação pode ser percebida comparando-se os resultados obtidos por Jentschel et al. (2007), os quais destacaram que sementes de capuchinha, em papel filtro, só apresentaram raízes e hipocótilos dez dias após a implantação do experimento. Os resultados são diferentes dos apresentados no presente trabalho, em que a germinação sobre papel apresentou a emissão da raiz mais rápida, demonstrando diferenças de comportamento, o que pode também estar relacionados à qualidade das sementes, pois, segundo Nascimento et al. (2011), sementes de alta qualidade apresentam rápida germinação, formando plântulas normais em curto espaço de tempo.

Desta maneira, os lotes de produtos vendidos e testados neste experimento são adequados à comercialização, pois, nas melhores condições ocorreu germinação em altas taxas, com produção de plântulas saudáveis. Porém, a espécie apresenta requisitos específicos para se atingir boas taxas de germinação e se as condições não forem adequadas, ocorre uma redução significativa no processo.

Os resultados de crescimento obtidos em câmara de germinação indicaram que, na interação de fatores, as melhores médias de crescimento foram encontradas no substrato areia, temperaturas de 20 e $25^{\circ} \mathrm{C}$. Já a vermiculita apresentou o melhor crescimento $\left(20\right.$ e $\left.25^{\circ} \mathrm{C}\right)$ apenas para a parte aérea (Tabela 2).

Tabela 2. Crescimento da raiz e parte aérea $(\mathrm{mm})$ de capuchinha em câmara de germinação e, parte aérea em casa de vegetação, a diferentes temperaturas $\left({ }^{\circ} \mathrm{C}\right)$ e substratos. Campo Grande, 2018

\begin{tabular}{|c|c|c|c|c|c|c|c|}
\hline \multirow{2}{*}{$\frac{\text { Câmara de germinação }}{\text { Interação }}$} & \multicolumn{3}{|c|}{ Comprimento Raiz (mm) } & \multicolumn{3}{|c|}{ Comprimento Parte Aérea (mm) } & \multirow[b]{2}{*}{ Verm } \\
\hline & Areia & Papel & Verm* & Interação & Areia & Papel & \\
\hline $20^{\circ} \mathrm{C}$ & $70^{\mathrm{aA}}$ & $8,7^{\mathrm{aC}}$ & $29,9^{\mathrm{aB}}$ & $20^{\circ} \mathrm{C}$ & $19,3^{\mathrm{aA}}$ & $2,7^{\mathrm{bB}}$ & $20,5^{\mathrm{aA}}$ \\
\hline $25^{\circ} \mathrm{C}$ & $72^{\mathrm{aA}}$ & $9,4^{\mathrm{ac}}$ & $26,3^{a B}$ & $25^{\circ} \mathrm{C}$ & $18,9^{\mathrm{aA}}$ & $4,4^{a B}$ & $22,5^{\mathrm{aA}}$ \\
\hline $30^{\circ} \mathrm{C}$ & $7,0^{\mathrm{dA}}$ & $0,8^{\mathrm{cC}}$ & $4,5^{\mathrm{dB}}$ & $30^{\circ} \mathrm{C}$ & 0 & $0,7^{\mathrm{CB}}$ & $15,3^{\mathrm{bA}}$ \\
\hline $35^{\circ} \mathrm{C}$ & 0 & 0 & 0 & $35^{\circ} \mathrm{C}$ & 0 & 0 & 0 \\
\hline $20-30^{\circ} \mathrm{C}$ & $50,4^{\mathrm{bA}}$ & $6,2^{b c}$ & $15,6^{\mathrm{bB}}$ & $20-30^{\circ} \mathrm{C}$ & $17,3^{\mathrm{bA}}$ & $4,5^{a B}$ & $16,8^{\mathrm{bA}}$ \\
\hline $25-35^{\circ} \mathrm{C}$ & $15,4^{\mathrm{cA}}$ & $1,0^{c C}$ & $8,6^{\mathrm{CB}}$ & $25-35^{\circ} \mathrm{C}$ & $14,4^{\mathrm{cA}}$ & $0,8^{\mathrm{cB}}$ & $12,4^{\mathrm{cA}}$ \\
\hline \multicolumn{8}{|c|}{ Casa de vegetação - Crescimento Parte Aérea $(\mathrm{mm})$} \\
\hline & & \multicolumn{3}{|c|}{$\mathbf{5 0 \% \text { luz }}$} & \multicolumn{3}{|c|}{$70 \%$ luz } \\
\hline T1 - Testemunha & & \multicolumn{3}{|c|}{$12,2^{\mathrm{aA}}$} & \multicolumn{3}{|c|}{$13,4^{\mathrm{aA}}$} \\
\hline T2 - Testemunha química & & \multicolumn{3}{|c|}{$10,9^{\mathrm{abA}}$} & \multicolumn{3}{|c|}{$10,3^{b c A}$} \\
\hline T3 - Torta de Filtro $20 \%$ & & \multicolumn{3}{|c|}{$11,8^{\mathrm{aA}}$} & \multicolumn{3}{|c|}{$10,4^{\mathrm{bcA}}$} \\
\hline T4 - Torta de Filtro $40 \%$ & & \multicolumn{3}{|c|}{$10,2^{\mathrm{bA}}$} & \multicolumn{3}{|c|}{$11,5^{\mathrm{abA}}$} \\
\hline T5 - Cama de Frango $20 \%$ & & \multicolumn{3}{|c|}{$10,1^{\mathrm{bA}}$} & \multicolumn{3}{|c|}{$9,1^{\mathrm{bcA}}$} \\
\hline T6 - Esterco Bovino $20 \%$ & & \multicolumn{3}{|c|}{$10,4^{\mathrm{bA}}$} & \multicolumn{3}{|c|}{$10,9^{\mathrm{abcA}}$} \\
\hline T7 - Esterco Ovino $20 \%$ & & \multicolumn{3}{|c|}{$11,9^{\mathrm{aA}}$} & \multicolumn{3}{|c|}{$8,3^{c B}$} \\
\hline T8 - Esterco Ovino $40 \%$ & & \multicolumn{3}{|c|}{$10,9^{\mathrm{abA}}$} & \multicolumn{3}{|c|}{$10,8^{\mathrm{abcA}}$} \\
\hline T9 - Esterco de Coelho $20 \%$ & & \multicolumn{3}{|c|}{$9,1^{\mathrm{bA}}$} & \multicolumn{3}{|c|}{$7,9^{\mathrm{CA}}$} \\
\hline T10 - Esterco de Coelho $40 \%$ & & \multicolumn{3}{|c|}{$7,8^{\mathrm{cB}}$} & \multicolumn{3}{|c|}{$10,2^{\mathrm{bcA}}$} \\
\hline
\end{tabular}

*Verm = vermiculita. Médias seguidas de mesma letra (minúsculas para colunas, maiúsculas para linhas) não diferem entre si, pelo teste $\mathrm{t}$ ( $5 \%$ de probabilidade).

Novamente, as temperaturas mais elevadas não foram adequadas, prejudicando a formação das estruturas vegetativas, indiferente dos substratos utilizados. Essas temperaturas tendem a dificultar a germinação e, consequentemente, o crescimento das plântulas. Desta maneira, quanto maior a temperatura, menores foram as médias de crescimento, até mesmo não ocorrendo a germinação $\left(35^{\circ} \mathrm{C}\right)$ (Tabelas 1 e 2).

Também, pode ser observado que a temperatura alternada de $20-30^{\circ} \mathrm{C}$, que foi adequada para a protrusão da raiz, não propiciou um bom desenvolvimento das plântulas. Assim, deve-se levar em conta a facilidade que o substrato oferece para o desenvolvimento das plântulas resultantes da germinação (BRASIL, 2009).

Estudos de Silva et al. (2008), trabalhando com o almeirão (Cichorium intybus L.), obtiveram melhores resultados frente ao substrato areia. Por outro lado, Honório et al. (2011), trabalhando com o jambu (Spilanthes oleracea L.), relataram menor comprimento das raízes quando as sementes da espécie foram expostas ao substrato areia. 
Os resultados obtidos indicam que, após a germinação, o ideal seria transplantar as plântulas para substratos com a presença de areia, permitindo sua formação mais vigorosa. Porém esse substrato não apresenta os nutrientes necessários para manter um crescimento adequado. Assim, o posterior transplante para ambientes mais férteis poderia ser necessário, embora a espécie cresça bem em diferentes substratos.

Avaliando-se o crescimento das plantas em casa de vegetação no segundo ensaio (Tabela 2), a espécie demonstrou que pode crescer bem em menor ou maior luminosidade, em solos arenosos sem a adição de adubação, confirmando sua característica de espécie rústica. Assim, sua grande ocorrência em áreas abandonadas por culturas anteriores é explicada por sua plasticidade ambiental em solos com deficiência nutricional, além da capacidade de crescer em ambientes sombreados.

A adição de adubação química ou orgânica não produziu resultados superiores aos encontrados para o controle. Porém, a adição dos diferentes tipos de adubação, na dependência da luminosidade, produziu resultados distintos, sendo o substrato com esterco ovino (40\%), mais eficaz, nas duas luminosidades.

A adubação que não demonstrou eficiência em nenhuma luminosidade foi a cama de frango e o esterco de coelho. Em relação à cama de frango, a concentração $(20 \%)$ foi muito alta. De acordo com Rogeri et al. (2015), quando seu uso ocorre sem o material estar totalmente estabilizado, pode causar efeitos adversos à cultura e ao ambiente, inibindo o crescimento das plantas. Levando-se em consideração os dados apresentados, essa seria uma opção para explicar os resultados insatisfatórios, pois, de acordo com Oliveira et al. (2008), a utilização deste tipo de adubação propiciou um aumento significativo na produção de taro (Colocasia esculenta (L.) Schott).

Em relação à utilização do esterco de coelho, em que as plântulas apresentaram menor crescimento, talvez esse fator esteja relacionado a uma liberação mais demorada dos nutrientes contidos nesse tipo de esterco. Queiroz et al. (2014), trabalhando com milheto (Pennisetum americanum (L.) Leeke) não encontraram diferenças, no crescimento, em tratamentos com ou sem a presença desse adubo. Esses resultados estão relacionados ao fato de que esse tipo de esterco apresenta uma pequena fração de fácil biodegradação, se comparado a outros tipos, resultando na necessidade de um tempo maior para liberação de nutrientes no solo, o que não ocorreu no experimento.

Por outro lado, os melhores resultados demonstrados em T8 (40\% esterco ovino), nas duas intensidades luminosas, podem ser atribuídos aos nutrientes presentes em sua composição. De acordo com Simplício et al. (2004), esse esterco apresenta elevados teores de N, P e K, quando comparado a outros diferentes adubos orgânicos. Peixoto Filho et al. (2013), testando esterco de frango, bovino e ovino no cultivo de alface (Lactuca sativa L.), demonstraram que, a partir do segundo cultivo, o esterco ovino se destaca, resultado similar ao encontrado por este trabalho.

Os resultados distintos, em relação aos adubos utilizados e diferenças entre as taxas de crescimento, são justificados pelas diferentes taxas de liberação de nutrientes destas adubações, fator relacionado à composição do material orgânico utilizado (LEITE et al., 2003). Outro fator a ser avaliado, de acordo com Azeez et al. (2010), pode estar relacionado com as diferentes origens dos adubos, pois os tratamentos a que cada grupo animal foi submetido resultará em respostas diferenciadas, sendo que o animal produzirá, como resultado de sua alimentação, estercos com diferentes qualidades.

Apesar de todas essas variáveis, as modificações decorrentes da adubação orgânica nas propriedades físicas e químicas do solo podem influenciar de forma positiva a produtividade das plantas, justificando sua utilização. Esse tipo de adubação vem tomando espaço perante alguns tipos comerciais convencionais, principalmente na agricultura familiar; porém, são necessários mais estudos para avaliar seu real efeito frente às diferentes espécies.

Assim, cultivos de rápido crescimento necessitam ser associados a adubos que permitam uma rápida liberação de seus íons. Levando-se em consideração as características da capuchinha, para que possa ocorrer um maior efeito da adubação orgânica, talvez seja necessário um maior período para que a adubação possa causar mudanças mais significativas no crescimento, propiciando maior biomassa. 
Entretanto, a questão de que sempre seria esperado que a adubação resultasse um maior crescimento pode não ser totalmente correta. Muitas vezes ocorre influência genética na absorção de nutrientes, relacionada às características morfológicas, fisiológicas e evolutivas da planta. Assim, algumas espécies, quando colocadas em solos adubados, acumulam os íons sem alterar a taxa de crescimento, situação relacionada a sua história evolutiva de crescimento em solos pobres (MARSCHNER, 2012).

A diversidade de resultados encontradas no crescimento inicial em diferentes condições ambientais demonstra a alta adaptabilidade (plasticidade) da espécie e sua rusticidade, o que pode ser observado por meio do rendimento em T1 (solo arenoso sem adição de nutrientes). Carbonari et al. (2006) confirmam que a capuchinha é uma espécie rústica e de fácil cultivo e propagação, evidenciando o conceito de grande adaptação, o que justifica a sua presença em diversos países das Américas e da Europa.

Os resultados obtidos indicaram germinação rápida em câmara de germinação e, levando-se em consideração as variáveis germinação e vigor, a melhor condição foi encontrada na interação da temperatura de $25^{\circ} \mathrm{C}$, substrato vermiculita e $20-30^{\circ} \mathrm{C}$, substrato areia; no entanto, a melhor formação de plântulas foi obtida no substrato areia, temperatura de 20 e $25^{\circ} \mathrm{C}$.

O crescimento em casa de vegetação indicou que a espécie apresenta bom desenvolvimento em solos sem adição de adubação, química ou orgânica, em diferentes luminosidades, demonstrando que, para cultivos rápidos, não é necessário o processo de adubação, além de um grande potencial de adaptação da capuchinha a condições ambientais diversas, com bom rendimento de massa verde.

\section{Referências}

AZEEZ, J.O. et al. Differential responses in yield of pumpkin (Curcubita maxima L.) and night shade (Solaum retroflexum Dun.) to the aplication of three animal manures. Bioresource Technology, v.101, n.7, p.2499-2505, 2010.

BEWLEY, J.D. et al. Seeds: physiology of development, germination and dormancy. 3rd. New York: Springer, 2013. $392 \mathrm{p}$.

BRANCALION, P.H.S. et al. Temperatura ótima de germinação de sementes de espécies arbóreas brasileiras. Revista Brasileira de Sementes, v.32, n.4, p.15-21, 2010.

BRASIL. Ministério da Agricultura, Pecuária e Abastecimento. Regras para análise de sementes. Brasília: Secretaria de Defesa Agropecuária. Mapa/ACS, 2009. 399p.

CARBONARI, V.B. et al. Phosphorus and chicken manure on development and yield of Tropaeolum majus L. Brazilian Journal of Medicinal Plants, v.8, p.71-77, 2006.

CETNARSKI FILHO, R.; NOGUEIRA, A.C. Influência da temperatura na germinação de diásporos de Ocotea odorifera (Vellozo) Rohwer (canela-sassafrás). Ciência Florestal, v.14, p.191-198, 2005.

GASPAROTTO A. et al. Natriuretic and diuretic effects of Tropaeolum majus (Tropaeolaceae) in rats. Journal of Ethnopharmacology, v.122, p.517-522, 2009.

HONÓRIO, I.C.G. et al. Influência de diferentes substratos na germinação de jambu (Spilanthes oleracea L.Asteraceae). Biotemas, v.24, p.21-25, 2011.

JENTSCHEL, K. et al. Arbuscular mycorrhiza enhances auxin levels and alters auxin biosynthesis in Tropaeolum majus during early stages of colonization. Physiologia Plantarum, v.29, p.320-333, 2007.

KINUPP, V.F.; BARROS, I.B.I. Riqueza de plantas alimentícias não convencionais na Região Metropolitana de Porto Alegre, Rio Grande do Sul. Revista Brasileira de Biociências, v.15, p.63-65, 2007.

LEITE, L.F.C. et al. Estoques totais de carbono orgânico e seus compartimentos em argissolo sob floresta e sob milho cultivado com adubação mineral e orgânica. Revista Brasileira Ciências do Solo, v.27, p.821-832, 2003.

MAPA. Ministério da Agricultura, Pecuária e Abastecimento. Manual de hortaliças não-convencionais. Brasília: MAPA/ACS, 2010, 92p.

MARCOS FILHO, J. Fisiologia de sementes de plantas cultivadas. Piracicaba: FEALQ, 2005, 495p.

MARSCHNER, H. Mineral nutrition of higher plants. 3ed. London: Academic Press, 2012. 672p.

NASCIMENTO, W.M. et al. Qualidade da semente e estabelecimento de plantas de hortaliças no campo. In: NASCIMENTO, W.M. (ed). Hortaliças: tecnologia de produção de sementes. Brasília: Embrapa Hortaliças, 2011. p. 79-106.

OLIVEIRA, A.K.M. et al. Germinação de sementes de pau-de-espeto (Casearia gossypiosperma) em diferentes temperaturas. Revista Floresta, v.45, p.97-106, 2015. 
OLIVEIRA, F.L. et al. Desempenho de taro em função de doses de cama de aviário, sob sistema orgânico de produção. Horticultura Brasileira, v.26, p.149-153, 2008.

PEIXOTO FILHO, J.U. et al. Produtividade de alface com doses de esterco de frango, bovino e ovino em cultivos sucessivos. Revista Brasileira de Engenharia Agrícola e Ambiental, v.17, p.419-424, 2013.

QUEIROZ, C.R.A.A. et al. Esterco de coelho: fonte de nutrientes para complementação da adubação. Revista Agrogeoambiental, v.6, p.11-17, 2014.

RIBEIRO, W.S. et al. Capuchinha (Tropaeolum majus L.). Brasília: Editora Kiron, 2012, 100p.

ROGERI, D.A. et al. Mineralização e nitrificação do nitrogênio proveniente da cama de aves aplicada ao solo. Revista Brasileira de Engenharia Agrícola e Ambiental, v.19, n.6, p.534-540, 2015.

SIMPLíCIO, A.A. et al. A caprino-ovinocultura de corte como alternativa para a geração de emprego e renda. Sobral: Embrapa Caprinos, 2004, 44p.

SILVA, E.A. et al. Efeito de diferentes substratos na produção de mudas de cultivares de almeirão. Revista Agrarian, v.1, p.55-66, 2008.

SILVA, F.A.S.; AZEVEDO, C.A.V. The Assistat Software Version 7.7 and its use in the analysis of experimental data. African Journal of Agricultural Research, v.11, p.3733-3740, 2016. 